\title{
$\mathrm{PH} 9 \mathbf{8}_{\text {actualidad }}$
}

\section{No tengo tren}

A lo largo de los últimos años, el autor y su cámara fotográfica han recorrido distintas líneas ferroviarias, unas abandonadas y otras en declive, cuestionándose su decadencia cuando precisamente los retos del cambio climático avivan el debate sobre la sostenibilidad de los modelos poblacionales y la vertebración de sus comunicaciones terrestres, entre las que el tren convencional sirve a la población rural mejorando las marcas de eficiencia energética y de emisiones de $\mathrm{CO}^{2}$ tanto respecto del ferrocarril de alta velocidad como del transporte por carretera.

Luis Morales Padilla | fotógrafo

URL de la contribución <www.iaph.es/revistaph/index.php/revistaph/article/view/4434>

Los fenómenos de poblamiento territorial guardan relación directa con la expectativa de oportunidades de sus habitantes y con sus necesidades de servicios, y sobre ambos aspectos ha venido incidiendo el despliegue del ferrocarril en España desde sus inicios, actuando las obras públicas como foco de atracción de empleo y los transportes como motor de desarrollo industrial, comercial y cultural, mientras por otro lado la población se ha dotado de una infraestructura de servicios antes inexistentes. Este despliegue urdió una trama de obras de ingeniería, edificaciones, maquinaria, modos de vida y paisajes transformados que después han asistido de cerca a las sucesivas oleadas de despoblación en la llamada "España vacía". En aquellos elementos todavía activos sorprende la reiteración de los procesos de reducción de servicios, deterioro de sus instalaciones históricas, y posterior propuesta de recuperación para uso turístico como forma de revitalizar las economías locales.

Entretanto, la inversión en la red de alta velocidad supera en mucho a la de la convencional, y mientras la primera se ha consolidado como una de las más extensas del mundo, la degradación e incluso en ocasiones el abandono $^{1}$ resultan palpables en la segunda. Muchas voces han venido denunciando la marginación del tren convencional ${ }^{2}$, algo que determinados estudios académicos tachan de "irracional e ineficiente"3, pero estas críticas no han alcanzado mayor visibilidad en la opinión pública, que parece seguir asociando la alta velocidad con la idea de progreso y de modernidad impulsados por la ficción de unos recursos infinitos. Y quizá ese sea el relato ficti- cio que debemos combatir al reivindicar la vigencia y la utilidad de nuestro patrimonio ferroviario industrial.

\section{Fósiles en el mapa}

Las cosas definidas por su ausencia nos hablan sin la prepotencia de existir. Cuando la vieja materia de la realidad se transforma y su sustancia desaparece, sus huellas quedan a veces impresas en un sustrato más obstinado y duradero. La concha petrificada del molusco marino hallado en el monte parece fuera de lugar, pero nos cuenta cómo esas mismas tierras antes soportaban el peso de un océano. Al territorio le sucede algo parecido con el trasiego humano.

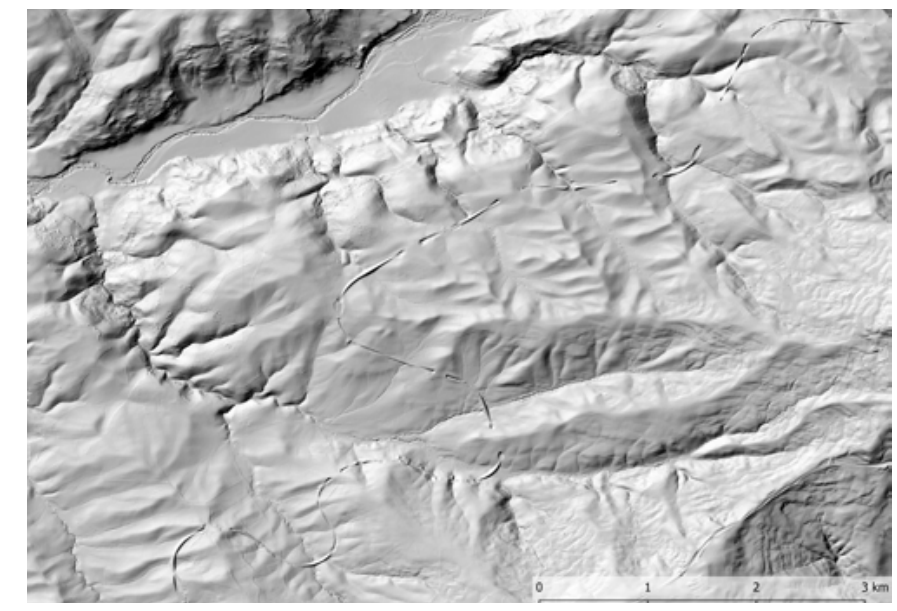

Sinuosidad y túneles del ferrocarril Baeza-Utiel en la comarca de Las Villas, al norte de Villacarrillo, Jaén | foto Instituto de Estadística y Cartografía de

Andalucía, bajo licencia CC BY 4.0. La generación de la imagen se ha realizado mediante procesamiento cuya fiabilidad es responsabilidad exclusiva del autor 
Los movimientos demográficos dejan un rastro físico impreso, muy palpable a partir de la Revolución Industrial, pero también complejo y desdibujado allí donde las transformaciones no cesan: en las grandes urbes. Es fuera de ellas donde la despoblación traza sus líneas en el paisaje. Y esas líneas, en el caso de los territorios que han tenido un cierto grado de desarrollo industrial, son ferroviarias.

Por ambición y por desdicha, de entre esas rutas fosilizadas en el mundo rural, destaca la malograda línea ferroviaria Baeza-Utiel. Ambiciosa porque, junto al resto del proyecto de Ferrocarril Transversal Baeza-Saint



Vista aérea del trazado del ferrocarril Baeza-Utiel y boca de salida del túnel de Las Colmenas en el término de Torreblascopedro, Jaén | foto Pedro Padilla

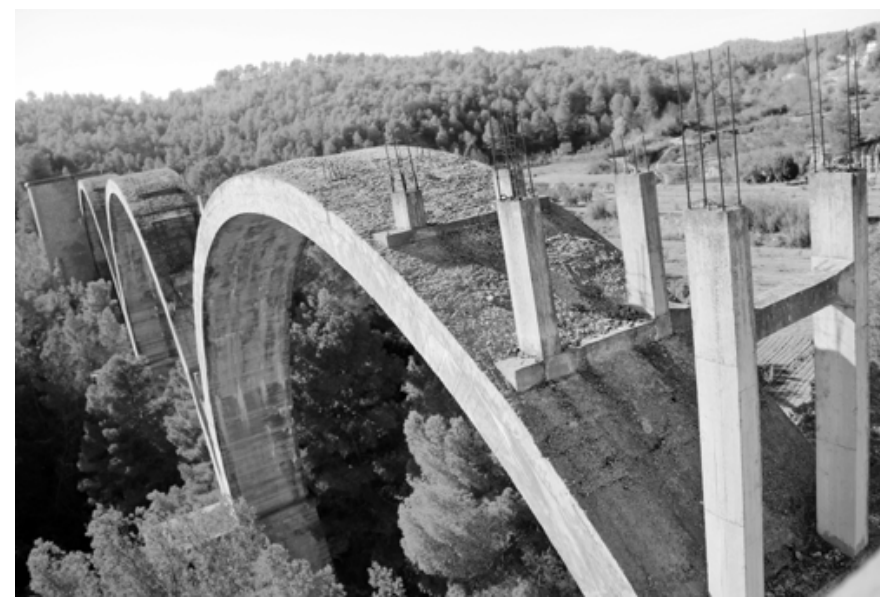

Viaducto inacabado sobre la Rambla del Tollo de Tortuga, conocido como "Puente Huerta Carreras", construido entre 1927 y 1934 para la línea ferroviaria Baeza-Utiel en Villamalea, Albacete | foto Luis Morales Padilla, autor de todas las imágenes si no se indica lo contrario
Girons, pretendía vertebrar algunas de las zonas más aisladas por el diseño ferroviario radial existente, comunicando Andalucía con la Europa continental no por la Meseta Central sino por el Levante peninsular: Baeza, Albacete, Utiel, Teruel, Alcañiz, Lérida y Pobla de Segur, hasta Saint Girons en Francia. Desdichada, porque la agonía del ferrocarril Baeza-Utiel propiamente dicho se prolongaría más de seis décadas, desde el inicio de las obras en 1927 hasta la reversión de los terrenos expropiados en 1992. El éxodo rural a partir de los años 60 y la generalización del transporte por carretera -hoy tan cuestionado por razones medioambientales- frenaron las expectativas de rentabilidad, y el Baeza-Utiel quedaría inconcluso para siempre, a pesar de haberse ejecutado el $78 \%$ de la inversión necesaria.

De aquel Transversal Baeza-Saint Girons tan solo entró en servicio parte del Ferrocarril Transpirenaico del Noguera Pallaresa, cuyos tramos entre Lérida y Pobla de Segur se concluyeron y han sobrevivido ${ }^{4}$ incluso a la traumática "racionalización" de $1985^{5}$, que supuso el cierre de otras muchas líneas "altamente deficitarias". Por su parte, tanto el ferrocarril Baeza-Utiel como el de Teruel-Alcañiz han sembrado un rosario de infraestructuras incorporadas al paisaje con una vastedad que rebasaría las categorías legales de protección patrimonial al uso. El reconocimiento de que gozan algunos de sus inmuebles queda limitado a sus aspectos arquitectónicos, inconexos y sin la perspectiva del resto de elementos que hilvanaron el proyecto, quizá porque involucran a distintas comunidades autónomas (Andalucía, Castilla-La Mancha y Valencia, en el primer caso; Aragón en el segundo), o quizá porque narran una historia de fracaso colectivo ${ }^{6}$.

\section{Cuatro décadas de chatarra}

Sabemos que la despoblación de un territorio constituye una amenaza para la pervivencia de su patrimonio cultural, pero también, a la inversa, es de temer el desmantelamiento de su patrimonio ferroviario como factor que contribuye a acelerar el vaciamiento de los pueblos. Cuando ese patrimonio tiene además algún valor cultural en sí mismo, los riesgos de pérdida se multiplican. Así, la demolición de un viaducto ferroviario metálico de finales del siglo XIX aún en servicio -que los hay- no 


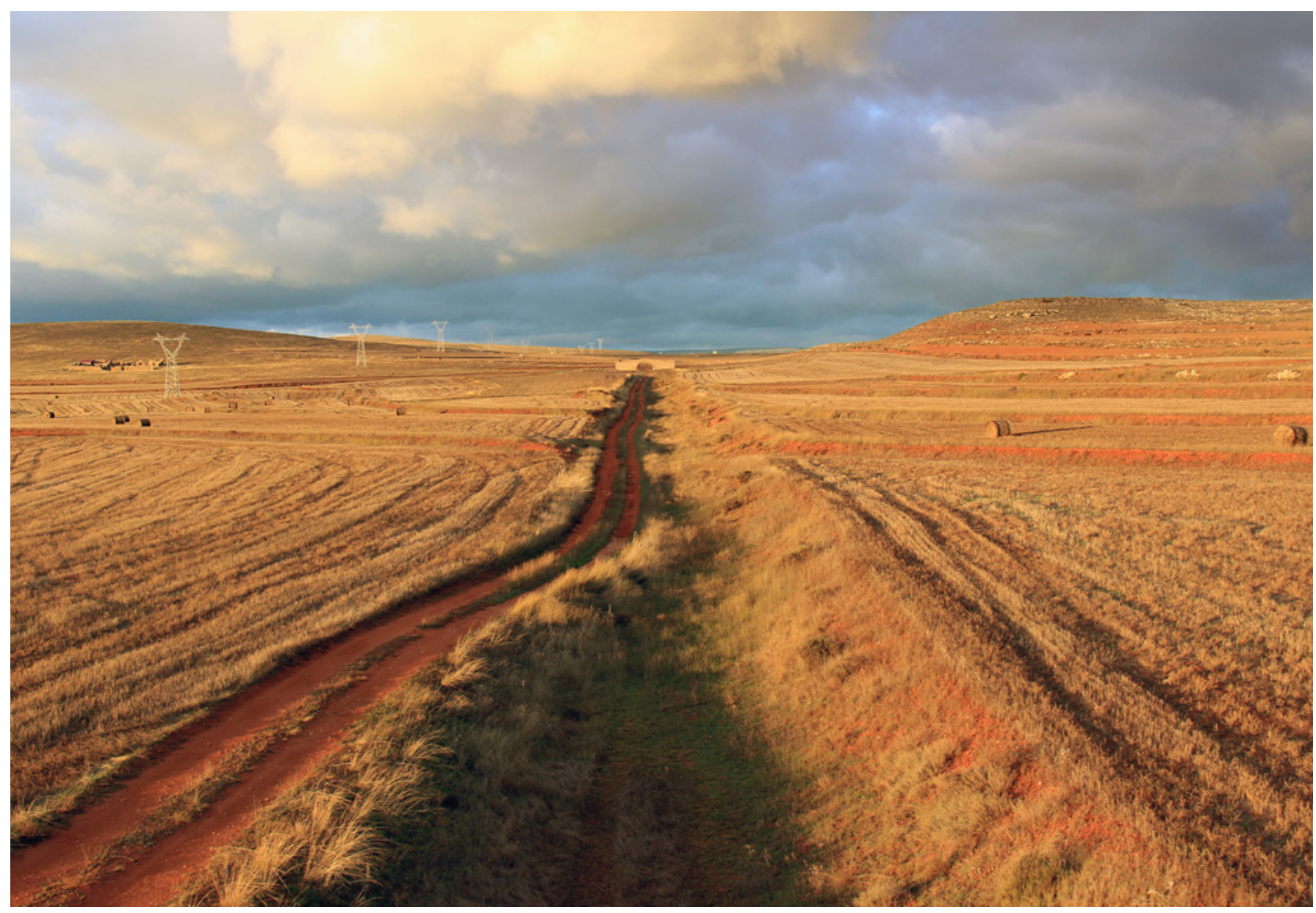

Trazado del ferrocarril Teruel-Alcañiz en el término de Orrios, Teruel

solo condenará un monumento industrial, también aislará a sus usuarios, habitantes de aquella población de provincias y a la sazón custodios de su castillo, del retablo barroco de su iglesia mayor y de su puente "romano", en realidad altomedieval.

En este sentido la prolongación de la vida activa de una infraestructura ferroviaria histórica y el mantenimiento inherente al servicio son la mejor garantía para la conservación de su valor cultural, acometiendo remodelaciones técnicas necesarias como las que en la década de los setenta se realizaron respetuosamente en el puente del Anchurón ${ }^{8}$ y en otros viaductos metálicos del ferrocarril Linares-Almería. En otros casos de esta línea se optó por la obra nueva, como sucedió en el puente Hacho, también en la provincia de Granada, donde se construyó un nuevo

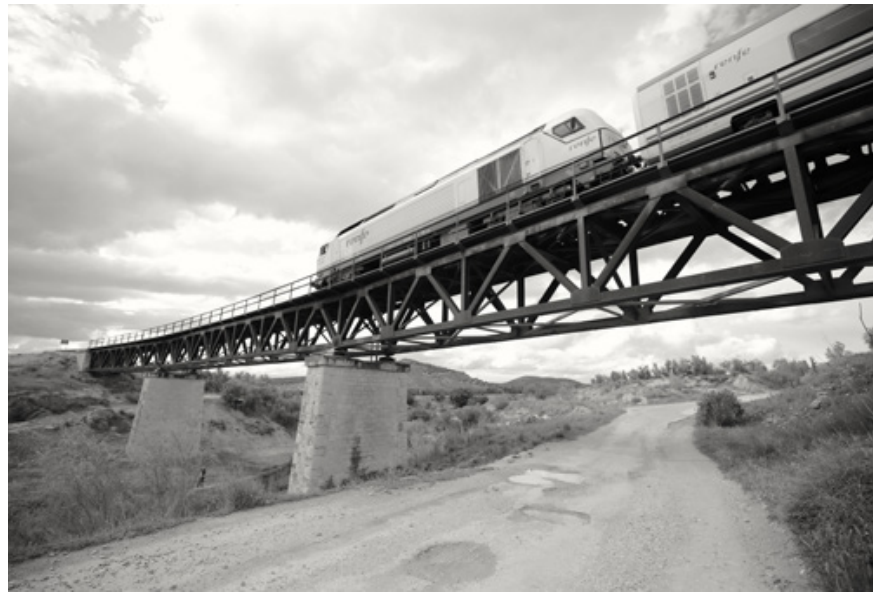

Viaducto del Jandulilla en el término de Úbeda, proyectado por la compañía Fives-Lille en 1890 y puesto en servicio en 1895 para la línea ferroviaria Linares-Almería 


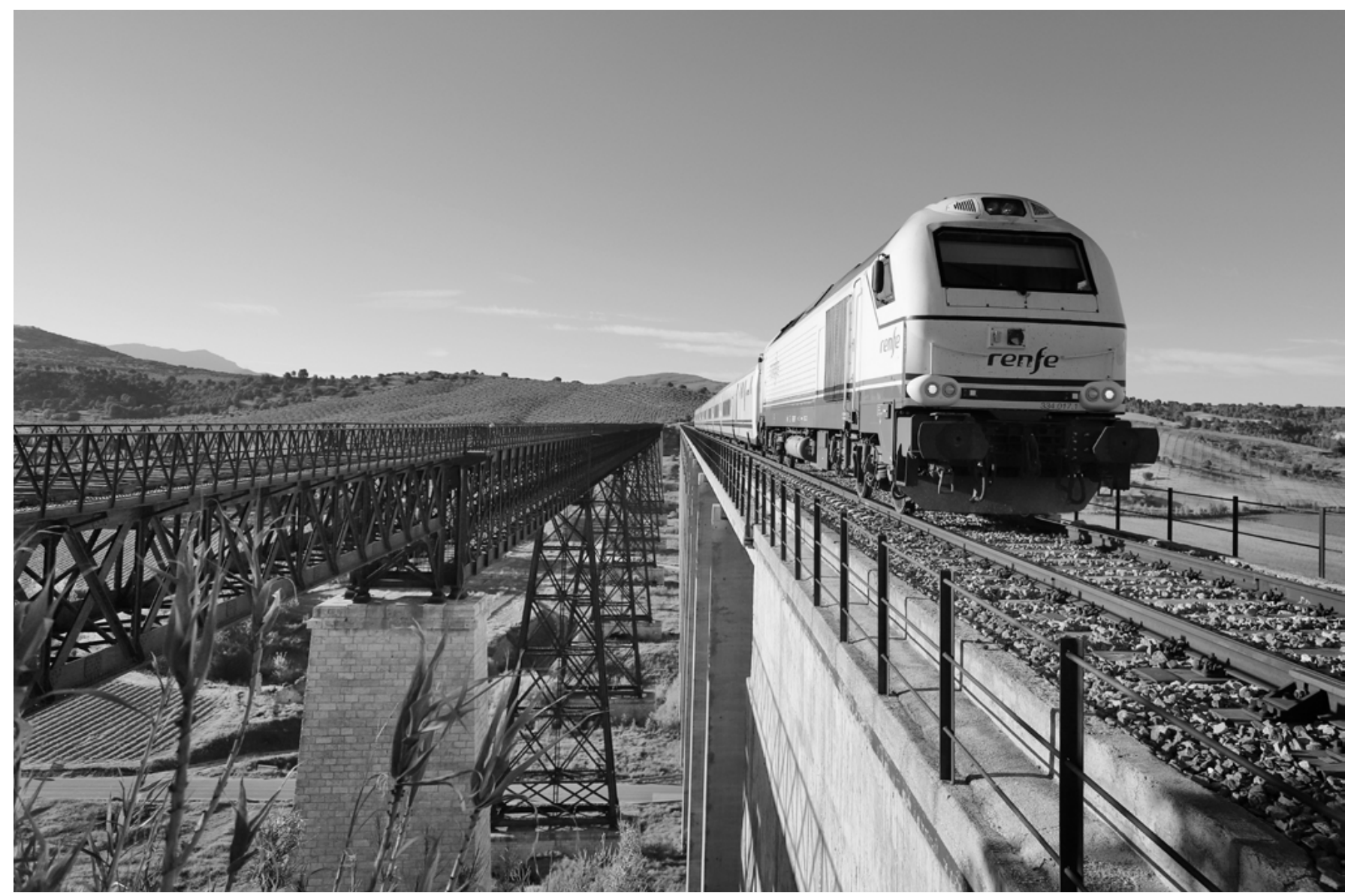

Puente de Hierro Hacho, de 624,60 m de longitud, en Guadahortuna, Granada. A su derecha, un tren TALGO circula sobre el puente de hormigón actualmente en servicio

viaducto paralelo al original, este último una joya industrial que como resultado y tras sobrevivir de milagro a la orden de demolición para su venta como chatarra, aguarda paciente a los trámites iniciados hace cuarenta años para su reconocimiento como bien de interés cultural.

\section{No tengo tren}

Hoy sin embargo la continuidad de los caminos de hierro en el mundo rural se ve confrontada con las políticas de alta velocidad, que por definición solo atienden a grandes núcleos de población ${ }^{9}$. El caso de la línea ferroviaria convencional de Cuenca a Utiel es un ejemplo vivo de ello. En los últimos años se han cerrado estaciones y suprimido servicios, y la línea, plagada de inmuebles de relevancia histórica resultado de la enorme inversión que esta obra pública supuso en su día en la comarca, presenta serios problemas de mantenimiento.

No tengo tren. No tengo tren. Es la frase que repetía el empleado que atendía la estación de Cuenca, el único allí presente un domingo por la tarde, a quienes se acercaban a la ventanilla para comprar billete en el Regional Express de las 17:40 h hacia Valencia ${ }^{10}$. Hablaba en primera persona, sin escudarse en una burocracia abstracta y remota. Él no tenía tren porque, según informaba, el convoy procedente de Aranjuez estaba parado en Huete por avería. No era un suceso aislado, uno de los motores del mismo regional fallaba un par de meses antes en la propia estación (AVERÍA, 2019). Son frecuentes los retrasos y transbordos repentinos. A veces el tren circula "sin calefacción y sin luz", según denuncia la 
Plataforma en Defensa del Ferrocarril (PLATAFORMA, 2019). Atrás quedaron los flamantes TALGO que en los años 70 volaban por los pueblos entre Aranjuez, Cuenca y Utiel. La vía y sus viejas traviesas todavía de madera ya no admiten aquellas velocidades, pero los trenes siguen cabeceando por la serranía sobre espectaculares hitos en la ingeniería ferroviaria: el viaducto de San Jorge, el del Cabriel, el del Imposible, el del Mira o el del Torres Quevedo...

Resultaba lógico el interés suscitado desde mediados del siglo XIX en unir por ferrocarril la capital de España con el Puerto de Valencia, uno de los más importantes de Europa y en la actualidad el segundo más importante del Mediterráneo ${ }^{11}$. Y, en efecto, en 1883 entraba en servicio la línea Madrid- Aranjuez-Cuenca, mientras que en 1885 por el Levante se inauguraba la de ValenciaUtiel. Entre ambos tramos, la serranía de Cuenca y sus caprichosas formas geológicas en uno de los territorios más despoblados de España, por lo que el ferrocarril de Cuenca a Utiel no se completaría hasta 1947 tras superar grandes dificultades ${ }^{12}$. Por su parte, las estaciones originales de este tramo habían sido diseñadas durante la Segunda República por el arquitecto y urbanista Secundino Zuazo, académico de la de Bellas Artes de San Fernando, y con desigual grado de conservación subsisten en pie a excepción de la de Víllora, que fue demolida por ADIF ya entrado el presente siglo ${ }^{13}$.

\section{Una farola, por favor}

En varias de estas estaciones se ha suprimido el servicio de viajeros, otras se mantienen como parada facultativa, desafectado total o parcialmente el edificio de viajeros. La mayoría han sido cedidas a la Diputación de Cuenca para el ambicioso proyecto Serranía en Vía (DIPUTACIÓN, 2018), consistente en su rehabilitación para el emplazamiento de actividades deportivas, turísticas y culturales de todo tipo, salvo el transporte ordinario de personas y mercancías, mientras la Fundación Nacional de Ferrocarriles Españoles baraja un proyecto de tren turístico.

La Carta de Sevilla de Patrimonio Industrial 2018 (SOBRINO SIMAL; SANZ CARLOS, 2019) recomienda con acierto: "La museología de la técnica, de la ciencia



Un "camello" automotor diésel-hidráulico cruza el viaducto de San Jorge en dirección a Cuenca

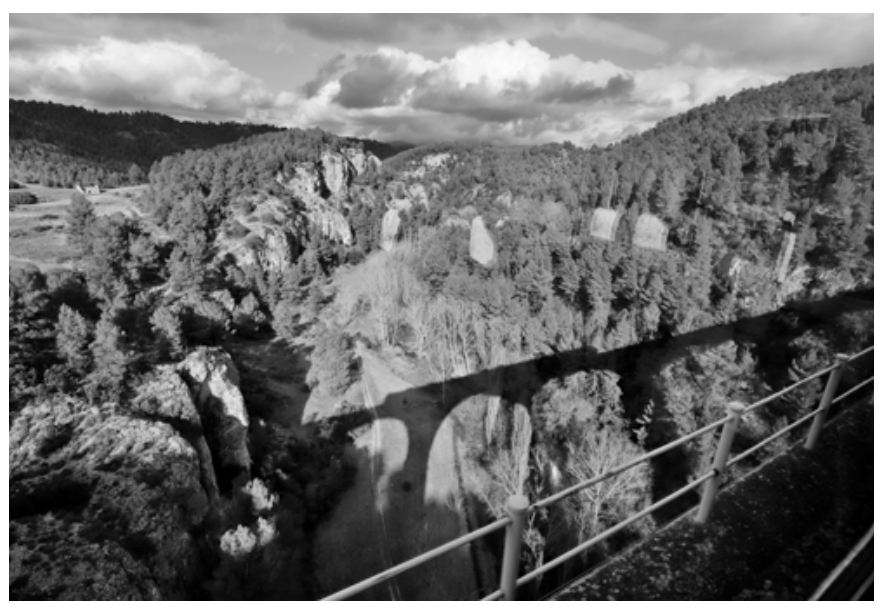

Viaducto del Mira o puente de Villapaz, desde el interior del tren

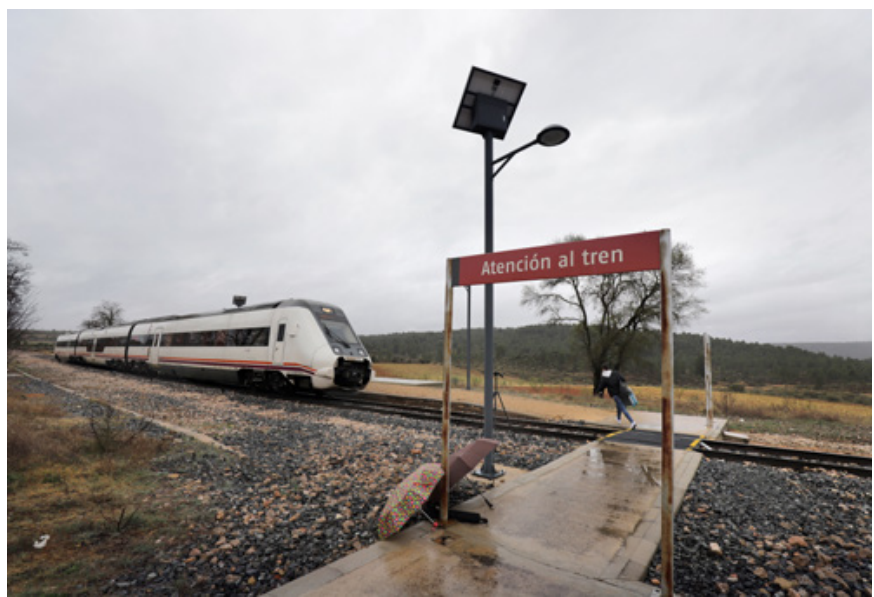

Apeadero de Víllora, Cuenca, tras la demolición de edificios de la estación 
o de la industria, debe ser reconsiderada a la luz de sus inequívocas funciones como constructora de relatos que deben ser integrales e inclusivos y facilitar un espacio de generación de procesos activos y de relatos abiertos a la educación técnica de la ciudadanía".

No obstante, debemos ser críticos con aquellos relatos que contribuyen a legitimar la pérdida.

La de Cañada del Hoyo es una de las estaciones del ferrocarril Cuenca-Utiel en proceso de rehabilitación. Aunque la parada facultativa del tren se mantiene para dar servicio a la pequeña localidad del mismo nombre, el edificio de viajeros se ha desafectado del servicio ferroviario, disponiéndose una precaria marquesina en su lugar. El inmueble fue cedido a un albergue temático donde se venían realizando actividades basadas en las aventuras del personaje literario Harry Potter, en un proyecto cofinanciado con fondos europeos del programa LEADER. A la entrada, un cartel informa: "Europa invierte en las zonas rurales". Al otro lado, un panel bajo la marquesina tras la vía indica los horarios del tren y un número de teléfono de asistencia para el caso de retraso. Sobre el panel alguien ha escrito a mano: "iPongan una farola, por favor!".

\section{Atención, tren sin parada}

La megafonía se activa automáticamente al paso de los trenes en la estación de Jódar-Úbeda, agudizando la sensación de soledad. Atención, tren sin parada, insiste la locución grabada hasta hacerse inaudible cuando el silbato de la locomotora retumba en el aire con una oleada de efecto doppler. Desde el andén, el fotógrafo devuelve el saludo al maquinista con el brazo, sin saber que no volverá a ver pasar por allí el TALGO a Granada procedente de Madrid. Dos meses después, el mismo día que se inaugure el AVE Granada-Antequera ${ }^{14}$, aquel hará su último trayecto por la línea Moreda-Granada, un ramal del ferrocarril Linares-Almería con más de un siglo de historia.

Un gran despliegue de prensa se volcará en la inauguración con titulares sobre turismo y futuro, pero ese otro cierre simultáneo pasará desapercibido. No se mencionarán las comarcas rurales, la agricultura o el transporte de mercancías. Nudos ferroviarios de la red convencional como Linares-Baeza o Moreda seguirán languideciendo poco a poco ${ }^{15}$. Según lo planeado, el próximo paso será encauzar también los trenes de Almería por esa misma línea de alta velocidad, a principios de 2020. Lenta, metódicamente, a la vista de todos, la acción de la erosión resulta más fácilmente asimilable que la catástrofe repentina.

Ciento veinte años atrás se había construido para la misma línea de Linares-Almería el puente Curvo de Gobernador, a las afueras del pueblo del mismo nombre en la provincia de Granada. Llegado el momento de modernizarlo, su función fue reemplazada en 1972 por una variante en terraplén con paso inferior ${ }^{16}$, quedando el viaducto semienterrado y en desuso, pero intacto. $Y$ así continuó hasta junio de 1978, cuando RENFE sacó a subasta su desguace junto con el Puente Hacho, su coetáneo hermano mayor. Coincidiendo con la movilización para salvar a este último de la dinamita, en febrero de 1979 se incoaron expedientes para la declaración de ambos puentes como monumentos históricos, lo que supuso la prohibición de derribarlos, y finalmente en marzo de ese mismo año el BOE publicaba las respectivas resoluciones (RESOLUCIÓN, 1979).

Fue demasiado tarde para el puente de Gobernador. Cuatro meses antes, en noviembre de 1978, se había consumado la demolición de su tramo metálico. Los 218 metros de longitud de la estructura, del tipo Cruz de San Andrés, habían desaparecido, quedando solamente en pie sus estribos y la base de sus pilares de sillarejo, como muñones clamando al cielo. El industrial chatarrero que se adjudicó la subasta hubo de emplear semanas en desmontarlo pieza a pieza con los trenes circulando a pocos metros, pero nadie dio la voz de alarma. Ni RENFE, ni la prensa, ni las autoridades de la zona reaccionaron. Todo se hizo lenta, metódicamente, a plena luz del día, pero nadie lo vio. 


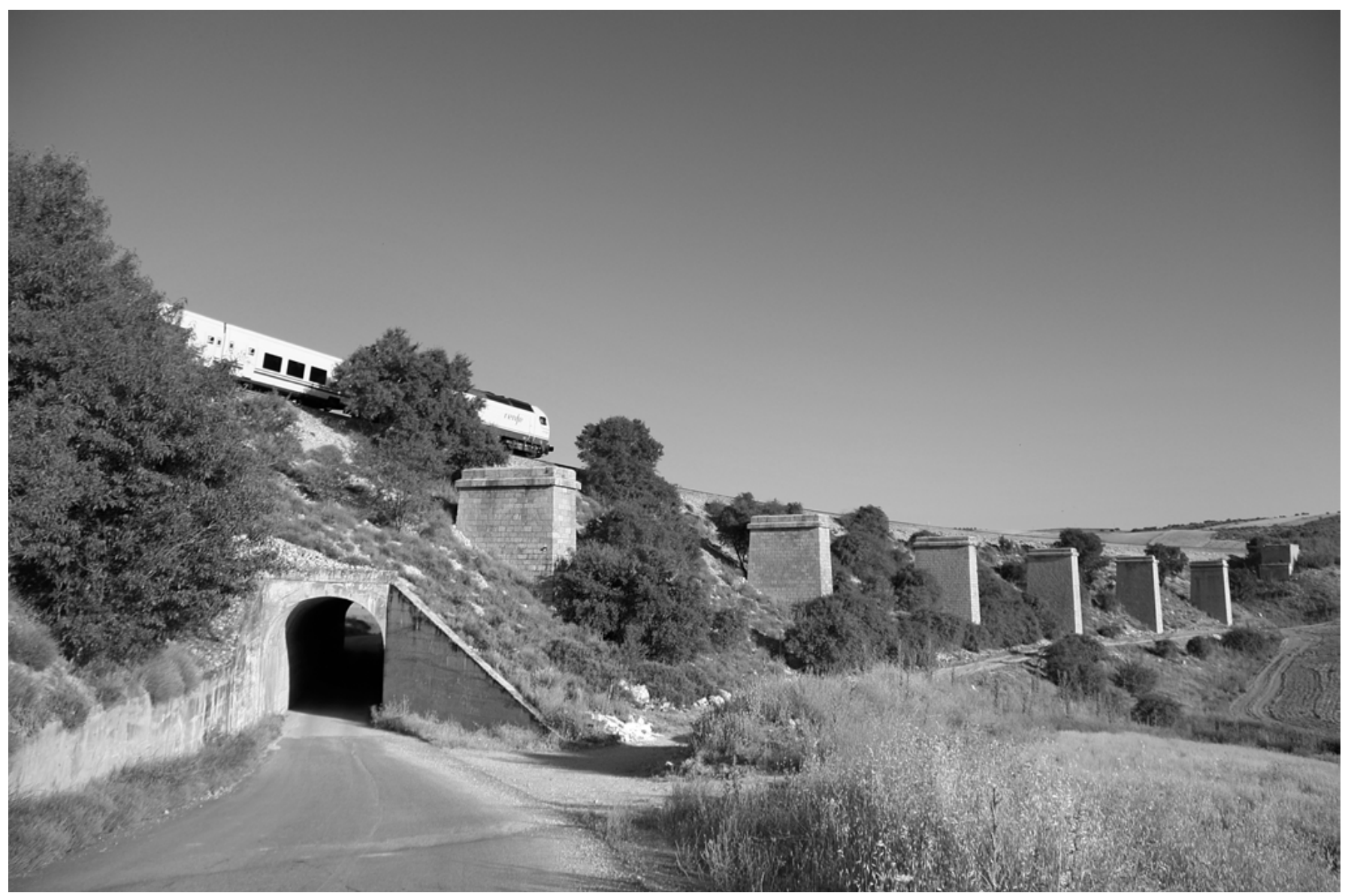

El TALGO Granada-Madrid Chamartín no 00371 avanza a primera hora de la mañana del 8 de junio de 2019 junto a las ruinas del Puente Curvo de Gobernador

\section{NOTAS}

1. Así, el servicio del Ferrocarril Directo Madrid-Burgos permanece en suspenso desde que en marzo de 2011 se produjo un desprendimiento en el túnel de Somosierra, sin que desde entonces se hayan emprendido las reparaciones previstas en la Ley del Sector Ferroviario para restablecer el tráfico en tales casos. Muy al contrario, en junio de 2018 las bocas del túnel fueron selladas con hormigón armado aunque, no obstante, la línea no se ha clausurado legalmente.

2. Ya en 1999 desde la Revista de la Asociación de Amigos del Ferrocarril de Almería se cuestionaba poner freno al AVE: "De todos es sabido que el AVE se caracteriza por dar servicio solamente a grandes ciudades en los extremos de las líneas, y alguna parada intermedia, im- posibilitando así servicios de gran interés social como los Regionales y Cercanías, y todo ello con un coste de construcción que a veces quintuplica el de una línea convencional de velocidad alta (en torno a los 160-220 $\mathrm{km} / \mathrm{h}$ ), sin olvidar el altísimo gasto de energía que es necesario para elevar los trenes a velocidades en torno a los 300 km/h y más altas" (ALCARAZ, 1999).

3. Según el informe "Aproximación a la geografía del despilfarro en España: balance de las últimas dos décadas", publicado en el Boletín de la Asociación de Geógrafos Españoles, "En España se ha realizado una asignación inadecuada de recursos públicos en materia de inversiones (incluidas importantes cantidades procedentes de los fondos europeos). Priorizando de manera irracional e ineficiente la inversión en infraestructuras como líneas de alta velocidad en detrimento de, por ejemplo, 
inversiones en educación, formación e innovación, o de inversiones en áreas de gran relevancia, como ferrocarril de cercanías o de media distancia que hubiera facilitado mejoras sustanciales en movilidad sostenible" (APROXIMACIÓN, 2018).

4. La línea fue finalmente transferida en 2004 a la Generalitat de Catalunya (REAL DECRETO, 2398/2004).

\section{Contrato-Programa Estado-RENFE, 1984-1986.}

6. Varios tramos del Baeza-Utiel se han transformado en vías verdes. En Jaén, la del Guadalimar (15,3 km) y la del Segura $(27 \mathrm{~km})$, y en Albacete la recientemente ampliada de la Sierra de Alcaraz $(71 \mathrm{~km})$. También una sección del ferrocarril Teruel-Alcañiz se señalizó en su momento como "Vía Verde de Valfambra" (por el río Alfambra). Denominaciones todas ellas que evocan su respectivo entorno natural aunque evitan el nombre de las líneas que recorren y su significación ferroviaria histórica. En una paradoja temporal, la de Alcaraz incluso añade en varios puntos la señalética de la Ruta de Don Quijote.

7. Sin ir más lejos, en el FFCC Linares-Almería, descritos con detalle en el artículo Gran viaducto sobre el Salado, en la línea de Linares a Almería. Corrimientos de los tramos metálicos (GRAN, 1899).

8. El aspecto del puente del Anchurón anterior a aquella remodelación había quedado inmortalizado en la película La India en Llamas (1959), dirigida por J. Lee Thompson y protagonizada por Lauren Bacall, que narra una huida en ferrocarril en la que este viaducto es protagonista escénico.

9. "Las plataformas de defensa del ferrocarril denuncian una verdadera estrategia para cerrar líneas. Dicha estrategia pasa por un abandono progresivo, descuidar el mantenimiento, encarecer los billetes, reducir la frecuencia de los trenes y dejar otros en horarios descabellados. Todo ello para que los usuarios renuncien a utilizar un transporte que no satisface sus necesidades, y acabar así esgrimiendo el poco uso de la línea como argumento para su cierre" (MARTíNEZ, 2018).
10. Regional Express 14162, con parada en Carboneras de Guadazaón, Yémeda-Cardenete, Camporrobles, Las Cuevas y Utiel, un trayecto con una duración de 2 horas 19 minutos al precio general de 10,35 € y que por la línea de alta velocidad AVE Madrid-Valencia puede realizarse también, sin paradas intermedias, entre Cuenca y Requena Utiel en solo 33 minutos al precio general de 30,30 € [consulta de tarifas y duración: 31/05/2019].

11. Por volumen de tráfico de contenedores, el Puerto de Valencia es el sexto de Europa y el segundo del Mediterráneo, tras el de Algeciras, de acuerdo con el ranking del World Shipping Council: <http://www.worldshipping. org/about-the-industry/global-trade/top-50-world-container-ports> [Consulta: 31/05/2019].

12. Los servicios de propaganda del régimen de Franco registraron la presencia del dictador en la inauguración oficial de la línea ferroviaria Cuenca a Utiel el 25 de noviembre de 1947. Dos secuencias de la película pueden visionarse en la Filmoteca Española, archivo NO-DO de 8 de diciembre de 1947: NOT N 257 A (http://www.rtve. es/filmoteca/no-do/not-257/1467422/) (minuto 07:17) y NOT N 257 B (http://www.rtve.es/filmoteca/no-do/not257/1467442/) (minuto 08:07) [Consulta: 31/05/2019].

13. En este aspecto ADIF actúa de forma expeditiva, y algunas administraciones locales denuncian no ser siquiera consultadas en la demolición de estaciones. De este modo, a finales de 2018 fue derribada la estación de Marmolejo (Jaén), en el $150^{\circ}$ aniversario de su construcción (MUÑOZ, 2018).

\section{El 25 de junio de 2019.}

15. Las provincias cuidadosamente rodeadas por las vías de alta velocidad, en teoría amigas de la línea recta, tampoco tienen garantizada la recompensa de un adecuado mantenimiento del tendido ferroviario convencional. En 2017 el Consejo Económico y Social de Jaén (DICTAMEN, 2017) diagnosticaba en todas las líneas de la provincia la "falta de mantenimiento y de conservación de las infraestructuras ferroviarias y de mejores elementos de seguridad que hacen que las velocidades sean menores". 
16. La Revista de Obras Públicas (REVISTA, 1973) dedicó una reseña a esta obra en su artículo Sustitución del puente de Gobernador en la línea férrea de Linares a Almería, P.K. 119/330, posteriormente reproducida en el compendio Los ferrocarriles de Andalucía en la Revista de Obras Públicas: 1853-2004 (CABALLERO CASADO; REY MUÑOZ; SÁNCHEZ LÁZARO).

\section{BIBLIOGRAFÍA}

- ALCARAZ, J. E.; (1999) ¿Hay que poner freno al AVE? Revista de la Asociación de Amigos del Ferrocarril de Almería [en línea] 7 de octubre de 1999 <http://asafal.es/hay-queponer-freno-al-ave> [Consulta 31/07/2019]

- Una AVERÍA obliga a la supresión de un tren regional en la línea Madrid-Cuenca-Valencia este domingo (2019) Voces de Cuenca [en línea] 5 de febrero de 2019 <http://www. vocesdecuenca.com/web/voces-de-cuenca/-/una-averiaobliga-a-la-supresion-de-un-tren-regional-en-la-linea-madridcuenca-valencia-este-domingo> [Consulta: 18/06/2019]

- CABALLERO CASADO, C.; REY MUÑOZ, R.; SÁNCHEZ LÁZARO, T. (2007) Los ferrocarriles de Andalucía en la Revista de Obras Públicas: 1853-2004 [en línea]. Sevilla: Consejería de Obras Públicas y Transportes, $2007<$ https:// ws147.juntadeandalucia.es/obraspublicasyvivienda/ publicaciones/05\%20FERROCARRILES/ferrocarriles andalucia_en_la_rop/ferrocarriles_andalucia_en_la_rop.pdf $>$ [Consulta: 25/07/2019]

- DICTAMEN de 25 de octubre de 2017 del Consejo Económico y Social de la Provincia de Jaén Situación del ferrocarril y propuestas de mejora de los servicios ferroviarios de la provincia de Jaén (2017) [en línea] Jaén: Diputación Provincial de Jaén, 2017 <https://www.dipujaen.es/export/files/ dipujaen/cesjaen/dictamen situacion_ferrocarril_propuestas mejora.pdf> [Consulta: 04/07/2019]

- DIPUTACIÓN da a conocer en Cardenete el Plan de Recuperación de Antiguas Estaciones de Tren "Serranía en vía" [en línea] (2018) Diputación Provincial de Cuenca, 23 de agosto de 2018 <https://www.dipucuenca.es/noticias/-/ publicador/diputacion-da-a-conocer-en-cardenete-el-plan-derecuperacion-de-antiguas-estaciones-de-tren-serrania-en-via-/ WFtHIM4Ja8SC> [Consulta: 18/06/2019]

- GRAN viaducto sobre el Salado, en la línea de Linares a Almería. Corrimientos de los tramos metálicos (1899) Revista de Obras Públicas [en línea], 46, tomo I (1215), pp. $\quad 9-12 \quad<$ http://ropdigital.ciccp.es/detalle_articulo. php?registro $=7760 \&$ numero_revista $=1215$ \&anio=1899\&anio_ ini=1890\&anio_fin=1899> [Consulta: 18/06/2019]

- MARTÍNEZ, R. (2018) Tren convencional vs. AVE: "Lo que hace el AVE es que nuestros hijos se marchen todavía más deprisa de aquí". Público [en línea] 30 de septiembre de 2018 $<$ https://www. publico.es/politica/ave-hijos-marchen-todaviamas-deprisa.html> [Consulta: 18/06/2019]

- MUÑOZ, R. (2018) Adif explica sus motivos para derribar la antigua estación de ferrocarril de Marmolejo. Cadena Ser [en línea] 14 de diciembre de 2018 <https://cadenaser.com/ emisora/2018/12/14/ser andujar/1544786887 595381.html> [Consulta: 18/06/2019]

- La PLATAFORMA en Defensa del Ferrocarril denuncia que hay trenes que circulan "sin calefacción y sin luz" (2019) Voces de Cuenca [en línea] 20 de febrero de 2019 <http://www. vocesdecuenca.com/web/voces-de-cuenca/-/la-plataforma-endefensa-del-ferrocarril-denuncia-que-hay-trenes-que-circulansin-calefaccion-y-sin-luz-> [Consulta: 13/09/2019]

- REAL DECRETO 2398/2004, de 30 de diciembre, sobre traspaso a la Generalidad de Cataluña de la línea ferroviaria de titularidad del Estado «Lleida-La Pobla de Segur» y de las funciones y servicios de la Administración del Estado en materia de transporte por ferrocarril en relación con dicha línea. Boletín Oficial del Estado [en línea], n. ${ }^{\circ} 315$, de 31 de diciembre de 2004 <https://www.boe.es/boe/dias/2004/12/31/ pdfs/A42810-42812.pdf> [Consulta: 18/06/2019]

- RESOlUCIÓN de la Dirección General del Patrimonio Artístico, Archivos y Museos por la que se acuerda tener por incoado expediente de declaración de monumento históricoartístico el puente sobre el arroyo de Gobernador, en la línea férrea Linares-Almería, próximo a Gobernador (Granada). Boletín Oficial del Estado [en línea], n. ${ }^{\circ} 70$, de 22 de marzo de 1979, página $7080<$ https://www.boe.es/boe/dias/1979/03/22/ pdfs/A07080-07080.pdf> [Consulta: 04/07/2019]

- REVISTA de Obras Públicas (1973), vol. 120, n. 3.101 , septiembre de 1973, pp. 797-798

- SOBRINO SIMAL, J.; SANZ CARLOS, M. (ed.) (2019) Carta de Sevilla de Patrimonio Industrial 2018 Los retos del siglo XXI [en línea]. Sevilla: Fundación Pública Andaluza Centro de Estudios Andaluces, Consejería de la Presidencia, Administración Pública e Interior, Junta de Andalucía, 2019 <https:// www.centrodeestudiosandaluces.es/datos/factoriaideas/ FI00119 PaisajesIndustriales_ok_04022019.pdf> [Consulta: 18/06/2019]

- ROMERO, J.; BRANDIS, D.; DELGADO VIÑAS, C.; GARCÍA RODRÍGUEZ, J. L.; GÓMEZ MORENO, M. L.; OLCINA, J.; RULLÁN, O.; VERA-REBOLLO, J. F.; VICENTE RUFÍ, J. (2018) Aproximación a la Geografía del despilfarro en España: balance de las últimas dos décadas. Boletín de la Asociación de Geógrafos Españoles [en línea], 77, 2018, pp. 1-51 <http:// dx.doi.org/10.21138/bage.2533> [Consulta: 31/07/2019] 